\title{
Transplantation of bone marrow derived macrophages reduces markers of neuropathology in an APP/PS1 mouse model
}

\author{
Luís Costa-Marques ${ }^{1}$, Katrin Arnold ${ }^{2}$, Marie-Christine Pardon ${ }^{3}$, Christiane Leovsky², Samantha Swarbrick',
} Claire Fabian ${ }^{2}$ and Alexandra Stolzing ${ }^{1,4^{*}}$

\begin{abstract}
Background: We investigated early hallmarks of putative therapeutic effects following systemic transplantation of bone marrow derived macrophages (BM-M) in APP/PS1 transgenic mice.

Method: BM-M were transplanted into the tail vein and the animals analysed 1 month later.

Results: BM-M transplantation promoted the reduction of the amyloid beta [37-42] plaque number and size in the cortex and hippocampus of the treated mice, but no change in the more heavily modified pyroglutamate amyloid beta E3 plaques. The number of phenotypically 'small' microglia increased in the hippocampus. Astrocyte size decreased overall, indicating a reduction of activated astrocytes. Gene expression of interleukin 6 and 10, interferongamma, and prostaglandin E receptor 2 was significantly lower in the hippocampus, while interleukin 10 expression was elevated in the cortex of the treated mice.

Conclusions: BM-M systemically transplanted, promote a decrease in neuroinflammation and a limited reversion of amyloid pathology. This exploratory study may support the potential of BM-M or microglia-like cell therapy and further illuminates the mechanisms of action associated with such transplants.
\end{abstract}

Keywords: Amyloid beta, Microglia, Alzheimer's disease, Cell therapy, Neuroinflammation

\section{Background}

Microglia are a key protagonist in the central nervous system (CNS) immune system. They regulate amyloid beta $(A \beta)$ content through phagocytosis, playing a central role in the pathology and progression of Alzheimer's Disease (AD) [1-3].

Depending on the surrounding stimuli, microglia may assume either a more pro-inflammatory (M1) or antiinflammatory (M2) state [4], though this might be a fluid continuum [5]. Short-term microglial activation is a natural part of neuroprotection in the brain, contributing to $A \beta$ clearance [6], whereas chronic activation has been

\footnotetext{
*Correspondence: A.Stolzing@lboro.ac.uk; Stolzing@gmail.com

${ }^{1}$ Centre for Biological Engineering, School of Mechanical, Electrical and

Manufacturing Engineering, Loughborough University, Epinal Way, Loughborough, UK

${ }^{4}$ Leipzig University, Leipzig, Germany

Full list of author information is available at the end of the article
}

associated with promoting neurodegenerative disorders such as $A D$ [7-9]. As AD progresses microglia chronic activation becomes detrimental and triggers a progressive damaging cycle to the brain [9].

Therefore, an adjustment of dysfunctional microglia cells via, for example, the replenishment with young functional microglia, can be an effective therapeutic strategy. A few early reports have explored this idea [10-13], although with different cell types, delivery methods and $\mathrm{AD}$ animal models.

The first study was in rats using stereotactic amyloid injections and using brain-derived microglia [10]. Stereotactic inject of cells does induce damage in the brain and leads to inflammation un-related to the disease. The second study used monocytes which are less differentiated compared to our BM-M and known to be phagocytic less active [11]. The third study is close to the aim of our study 
as bone marrow derived microglia were transplanted, however this study explored the priming with IL-4 to derive M2-like microglia. The cells were not characterized beyond the use of CD206 as an M2 marker and no cell tracking data was provided [12]. In addition, this was again using a rat model in which stereotactic injections were used. Changes observed in this model does not capture the element of aging, focusing solely on the role of amyloid alone as a model for AD.

The aim of this study was on using the most appropriate AD model, cell production that is easily scalable and translatable as well as using well characterized cells.

\section{Material and methods}

\section{Animals}

Transgenic mice used were overexpressing human amyloid precursor protein (APPKM670/671NL) and presenilin-1 (PS1L166P) under Thy-1 promoter control (age 16-19 months) (source: Dr. Mathias Jucker, Hertie-Institute for Clinical Brain Research, University of Tübingen, Germany). Mice were housed according to local regulations. Injections were performed by Dr. Pardon (Animal License Holder) under the project number 40/3601. 'Donor' $\mathrm{C} 57 \mathrm{Bl} / 6$ male young mice ( 3 months) for obtaining microglia were bred in the Leipzig University animal facilities (Landesdirektion Sachsen, License Number T 19/14).

\section{BM-M differentiation from bone marrow}

Femur and tibiae of young C57BL/6 mice were isolated with a scalpel. Each bone was placed in an Eppendorf tube and centrifuged, $400 \mathrm{~g}$ for $1 \mathrm{~min}$ at $4{ }^{\circ} \mathrm{C}$. The isolated pellet of bone marrow of one femur and one tibia of the same mouse was pooled and resuspended with DMEM low glucose (Gibco) with $1 \%$ penicillum/streptomycin (Gibco) and 10\% FBS (Hyclone). Afterwards, the cells were cultured in $100 \mathrm{~mm}$ petri dishes at $37^{\circ} \mathrm{C}, 5 \% \mathrm{CO}_{2}$ and $20 \% \mathrm{O}_{2}$ with medium change after 3 days. After 10 days the nonadherent bone marrow-derived stem cells were used for differentiation into microglia-like cells. In detail, the cell suspension was centrifuged, $200 \mathrm{~g}$ for $5 \mathrm{~min}$ at room temperature. The pellet was resuspended with a medium mix and placed on a $100 \mathrm{~mm}$ petri dish. This medium mix included one-part DMEM (low glucose $+10 \% \mathrm{FBS}$ ) with $20 \mathrm{ng} / \mathrm{ml}$ GM-CSF (Peprotec) and one part astrocyteconditioned DMEM medium, obtained from culturing astrocytes over $24 \mathrm{~h}$ in this medium. The differentiation took an additional 7 days without medium change by incubation at $37^{\circ} \mathrm{C}, 5 \% \mathrm{CO}_{2}$ and $20 \% \mathrm{O}_{2}$. All adherent cells were detached using trypsin and used for transplantation.

\section{Flow cytometry of microglia}

Briefly, cells were trypsinized and filtered through a $40 \mu \mathrm{m}$ filter and fixed with $2 \%(\mathrm{v} / \mathrm{v})$ paraformaldehyde (Pierce, 16\% Formaldehyde, Methanol-free) for $15 \mathrm{~min}$ at room temperature. Cells were centrifuged at $500 \mathrm{~g}$ for 5 min and washed with phosphate buffered saline (PBS). Subsequently a blocking step with $0.5 \%(\mathrm{v} / \mathrm{v})$ BSA for 30 $\mathrm{min}$ at room temperature. Cells for CD68 staining were permeabilized with $0.2 \%(\mathrm{v} / \mathrm{v})$ Tween 20 before blocking. Cells were incubated for $30 \mathrm{~min}$ at room temperature with fluorescence-labeled antibodies CD45-PE (1:100; MyltenyiREA737, 130-110-659), CD11b-PE (1:100; Myltenyi-REA592, 130-109-285); F4/80-PE (1:100; Myltenyi-REA126, 130-102422), CD68-PE (1:300; Myltenyi-FA11, 130-102-614), CD80PE (1:300; Myltenyi-16-10A1, 130-102-613), CD86 (1:300; Myltenyi-PO3.3, 130-102-604); MHCII (1:300; MyltenyiM5/114.15.2, 130-102-186), CD206-PE (1:300; Life technology- MR6F3, 12-2061-82), CD16/32-PE (1:100; MyltenyiREA377, 130-107-039), CD64-PE (1:100; Myltenyi-REA286, 130-103-808), CD169-PE (1:100; Myltenyi-REA197, 130-104953), CD204-PE (1:100; Myltenyi-REA148, 130-102-328), Dectin-PE (1:100; Myltenyi-REA154, 130-102-284), CD124PE (1:100; Myltenyi-REA235, 130-102-710), rat IgG2b isotype-PE (1:300; Myltenyi, 130-102-663), hamster IgG2 isotype (1:300; Thermo Fisher, 12-4888-81) and REA isotypePE (1:100; Myltenyi-130-104-628). Cells were washed again and fluorescence was measured using the BD Influx. Dot blot graphs were created using BD FACS ${ }^{\text {Tw }}$ Software. A gate for total cells was set on the FSC vs. SSC plot. PE was analysed using a $561 \mathrm{~nm}$ laser and a BP 585/29 filter. Marker expression analysis of the gated cells was done using the appropriate isotype as negative control.

\section{Transplantation}

$1 \times 10^{6}$ BM-M cells in $100 \mu \mathrm{l}$ PBS were injected into the tail vein of AD mice (16-19 months, $n=12)$. The control AD mice $(n=12)$ were injected with $100 \mu \mathrm{L}$ of PBS.

\section{Tissue preparation}

After 28 days from transplantation the mice were sacrificed and the brains were isolated for histology (BM-M, $n=6$; control $n=6$ ) and biochemical analysis (BM-M, $n=6$; control $n=6$ ). For biochemistry, mice were perfused transcardially post mortem with $0.9 \%(\mathrm{v} / \mathrm{v}) \mathrm{NaCl}$. Brains were removed, divided into regions (hippocampus, cortex, brainstem) and stored in peqGOLDTriFast ${ }^{\mathrm{m}}$ (PeqLab, 30-2040, Erlangen, Germany) at $-80^{\circ} \mathrm{C}$ until further use. For histology, mice were perfused transcardially post mortem with $0.9 \%(\mathrm{w} / \mathrm{v}) \mathrm{NaCl}$ followed by fixative containing $4 \%(\mathrm{v} / \mathrm{v})$ paraformaldehyde and $0.1 \%$ (v/v) glutaraldehyde in $0.1 \mathrm{M}$ phosphate buffer ( $\mathrm{pH}$ 7.4). Brains were removed and immersion-fixed overnight in the same fixative at $4{ }^{\circ} \mathrm{C}$. Brains were cryoprotected in $30 \%$ sucrose in $0.1 \mathrm{M}$ phosphate buffer ( $\mathrm{pH} 7.4$ ) with $0.1 \%(\mathrm{w} / \mathrm{v})$ sodium azide and cryosectioned into $20 \mu \mathrm{m}$ coronal sections with a cryomicrotome (Shandon CryotomeSME, Thermo Scientific) in frontal plane. Sections 
were collected in $0.1 \mathrm{M}$ phosphate buffer ( $\mathrm{pH}$ 7.4) with $0.1 \%$ sodium azide and stored at $4{ }^{\circ} \mathrm{C}$ until analysis.

\section{Immunohistochemistry}

Brain slices were washed twice with PBS- $0.05 \%$ (v/v) Tween 20 and incubated with blocking solution - $2 \%$ bovine serum albumin (Serva, \#47330), 0.3\% powdered milk (Applichem, \#A0830) and 0.5\% donkey serum (Jackson ImmunoResearch, \#017-000-001) for $30 \mathrm{~min}$ at room temperature. Slices were incubated with primary antibodies diluted in blocking buffer: anti-Iba-1 rabbit (1:200, Wako), $\beta$-amyloid (1:100, XP ${ }^{\circ}$ rabbit mAb, 8243S New England Biolabs), PyroGluAbeta pE3 (1:400, biotinylated monoclonal, Synaptic systems, 218,011 BT), Glial Fibrillary Acidic Protein (1:500, GFAP, Polyclonal, DAKO Z0334292) overnight at $4{ }^{\circ} \mathrm{C}$ in the dark. Slices were washed with PBS followed by incubation with the secondary antibody NorthernLights ${ }^{\mathrm{Tn}}$ Antirabbit IgG-NL637 (1:200, NL005), anti-mouse IgG NL557 (1:200, NL007) and anti-streptavidin (1:5000, NL999) for $1 \mathrm{~h}$ at RT. Slices were then incubated for 30 min with DAPI (1:
10,000; Sigma) at RT. Stained brain slices were mounted with ProLong ${ }^{\circ}$ Gold Antifade Mountant (Molecular Probes, P36934).

\section{Microscopy and image processing}

Images from the immunostained mice brain slides were captured with a Carl Zeiss AxioScan.Z1 slide scanner microscope, using ZEN blue (2012) software and acquired under the same exposure time settings for all the brains. Scan was performed under the 20x objective, at the wavelengths 545 nm (Zeiss 43 HE filter), $620 \mathrm{~nm}$ (Chroma ET49006 filter) or $365 \mathrm{~nm}$ (Zeiss $49 \mathrm{HE}$ filter) depending on the fluorophore. From each mouse, 3 brain sections were scanned and analysis was performed in the anterior, middle and posterior cortex, hippocampus and brainstem. ZEN blue (2012) slide scan software was used to visualize the sections images and to minimally adjust the image background. The number and area of $\mathrm{A} \beta$ positive plaques, Iba- 1 positive and GFAP positive cells were further evaluated and quantified using ImageJ software (tool of the public domain, https://imagej.
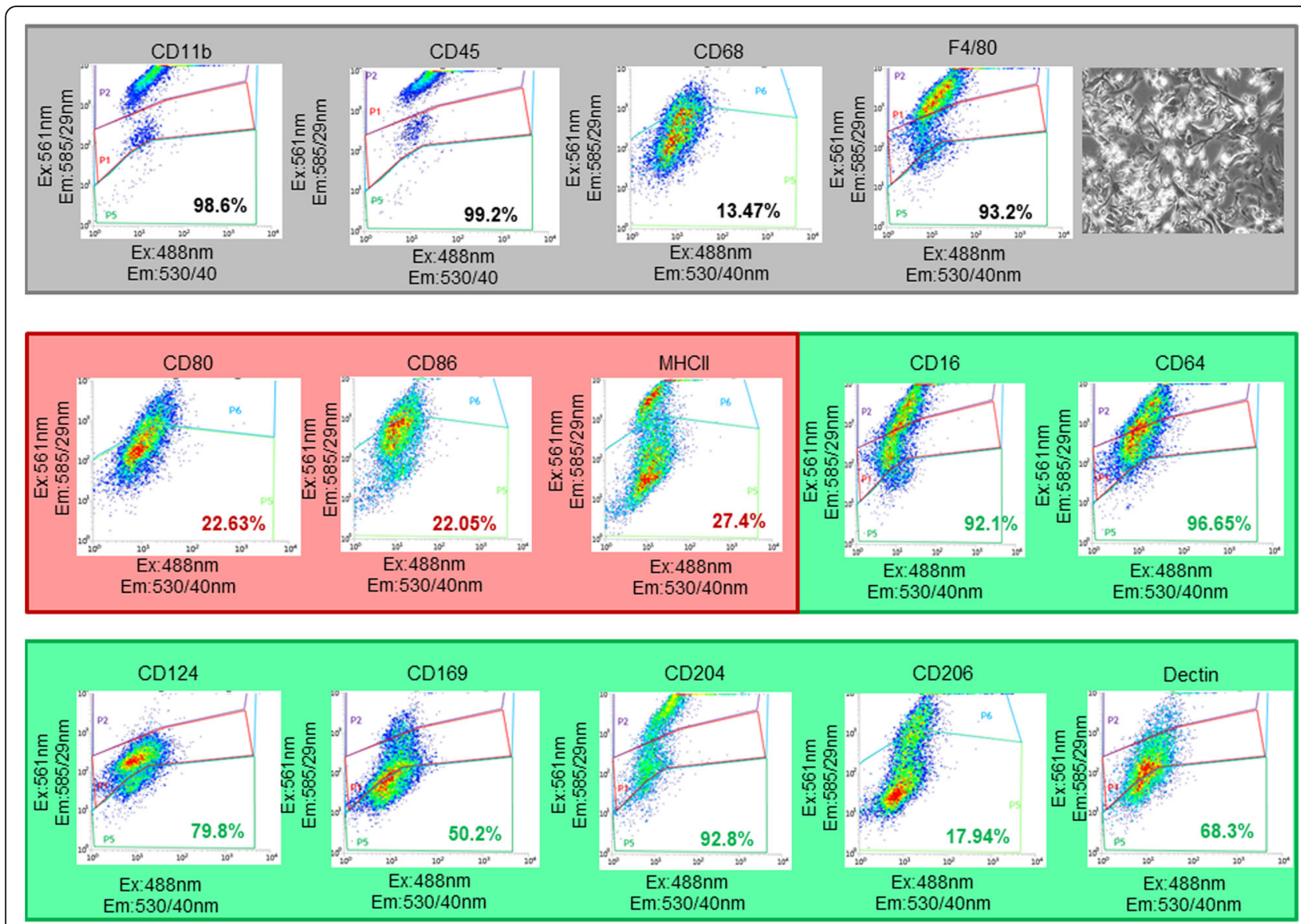

Fig. 1 Characterization of BM-M phenotype by flow cytometry. BM-M were positive for CD11b, CD45, CD68, CD206 and F4/80, which are general microglia markers. Levels of M2 specific microglia markers (CD16, CD64, CD169, CD124, CD204 and dectin) were higher than M1 markers (CD80, $\mathrm{CD} 86$, and $\mathrm{MHCII}$ ) indicating the prevalence of a microglia-M2 phenotype. At the top right a representative image of the transplanted BM-M is shown 
nih.gov/ij/). Images were initially converted to 8-bit channels, scale was set from pixels to $\mu \mathrm{m}$, threshold was established independently for each mouse and the region of interest was manually outlined and measured. The analyze particles function on Image $J$ (A $\beta$ plaques size set: 100 -infinity $\mu \mathrm{m}^{2}$; microglia size set: 100 -infinity $\mu \mathrm{m}^{2}$; circularity $0.00-1.00$ ) was used to determine number and area of plaques and microglia cells. Plaque number per $\mathrm{mm}^{2}$ was calculated using the counted number of plaques divided by the total measured region. Plaque size was calculated by dividing the total area covered of plaques by plaque number [14]. The same number and size calculations were made for subgroups of small, medium and large plaques $\left(100-500 \mu^{2}, 500-1500 \mu \mathrm{m}^{2}\right.$ and $>1500 \mu \mathrm{m}^{2}$, respectively) individually for total cortical, hippocampal or brainstem region. Calculations were performed in an unbiased manner by an investigator blind to the treatment conditions of the samples.

\section{RNA isolation and qRT-PCR}

RNA was extracted from hippocampus, cortex and brainstem using peqGOLDTriFastTM (PeqLab, 302040, Erlangen, Germany) reagent according to the manufacturer's instructions. RNA was treated with DNaseI (Life Technologies, EN0521) to remove genomic
DNA contamination. This procedure was followed by cDNA synthesis using Superscript III-reverse transcriptase (Life Technologies, 18,080,085) and Oligo (dT) $)_{18}$-Primers (Thermo Scientific, SO132) at $50^{\circ} \mathrm{C}$ for $1 \mathrm{~h}$. cDNA was used as PCR template in an 1:10 dilution and each sample run in triplicate. Quantitative PCR was performed on StepOnePlus ${ }^{\text {Tim }}$ Real-Time PCR System (Applied Biosystems) using Express SYBR GreenER qPCR Supermix Universal (Life technologies, 1,178, $401 \mathrm{~K}$ ), $0.2 \mu \mathrm{M}$ primer each on the DNA (primers as published by us before) with the following cycle conditions: primary denaturation at $95^{\circ} \mathrm{C}$ for $3 \mathrm{~min}$ at $95^{\circ} \mathrm{C}, 35$ cycles with 30 s at $95^{\circ} \mathrm{C}, 30$ s at $60^{\circ} \mathrm{C}$ and 30 s at $72{ }^{\circ} \mathrm{C}$ followed by fluorescence measurement. Absolute quantification was performed for every single gene with three technical repeats per sample. Serial dilutions of plasmid controls with known molecule concentrations were used as a positive control and to generate standard curves. Expression of target genes were normalized using 36B4 (large ribosomal protein P0, RPLP0) as reference gene.

\section{Elisa}

Glial fibrillary acidic protein (GFAP) (NS830, Merck), mouse triggering receptor expressed on myeloid cells 2 (TREM-2) (CSB-EL024405MO, Generon) and acetylcholinesterase

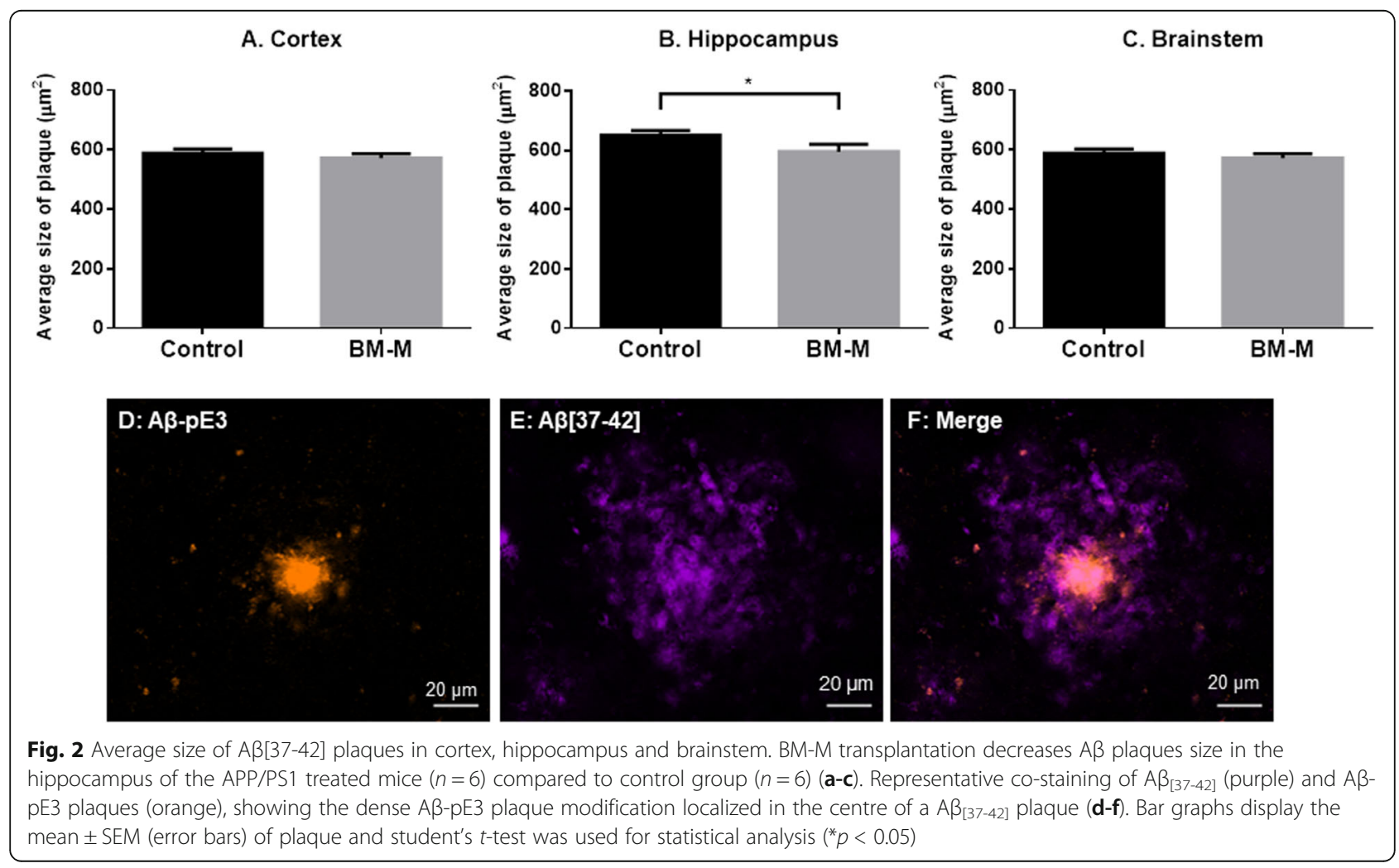


(AChE) (E-EL-M2637, Generon) were quantified by enzyme-linked immunosorbent assay (ELISA) kit, as per the manufacturer's instructions. Protein isolation was done by ethanol-bromochloropropane-water method according to Chey et al. [15] followed by further detergent removal with Compat-Able ${ }^{\mathrm{Tm}}$ BCA Protein Assay Kit (cat no. 23229, Thermofisher Scientific). The colorimetric signal was quantified using a plate reader (Fluostar Omega, BMG Labtech). Protein concentrations were calculated from the absorbance data (at $450 \mathrm{~nm}$ ) and were normalized to total protein content determined by Pierce ${ }^{\mathrm{ma}}$ BCA Protein Assay Kit (cat no. 23225, Thermofisher Scientific).

\section{Statistical analysis}

Statistical analysis was performed using the GraphPad Prism 6 (GraphPad Software). Data were tested for normality using the D'Agostino-Pearson omnibus normality test. Values between two groups were compared by the two-tailed unpaired Student's t test for normally distributed data. $P$ values of $p<0.05\left(^{*}\right), p<0.01\left(^{*}\right)$ and $p<$ $\left.0.01{ }^{(* * *)}\right)$ were considered significant.

\section{Results}

\section{BM-M characterization}

Prior to transplantation, the BM-M were exposed astrocyte conditioned medium and cell viability measurement was performed (BM-M viability $>90 \%$ ). These conditioned BM-M were positive for CD11b, CD45, CD68 and F4/80, which are general microglia markers (Fig. 1). In addition, we stained the cells for M1 and M2 markers and found the BM-M to be mainly of a microglia-M2 phenotype (CD16, CD64, CD169, CD124, CD204, CD206 and dectin). M1 markers (CD 80, CD86, and MHCII) expression levels were low (<30\%).

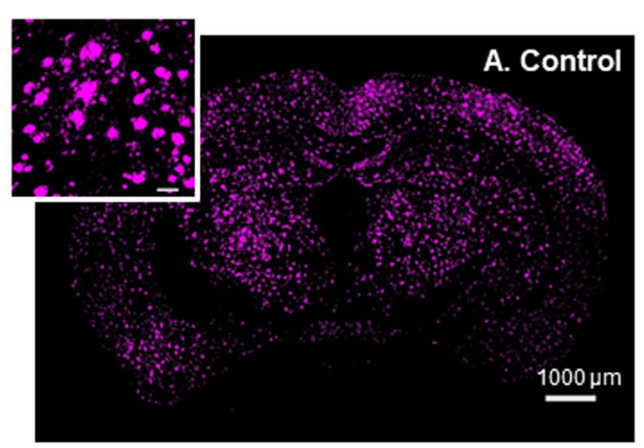

C. Small $A \beta_{[37-42]}$ plaques
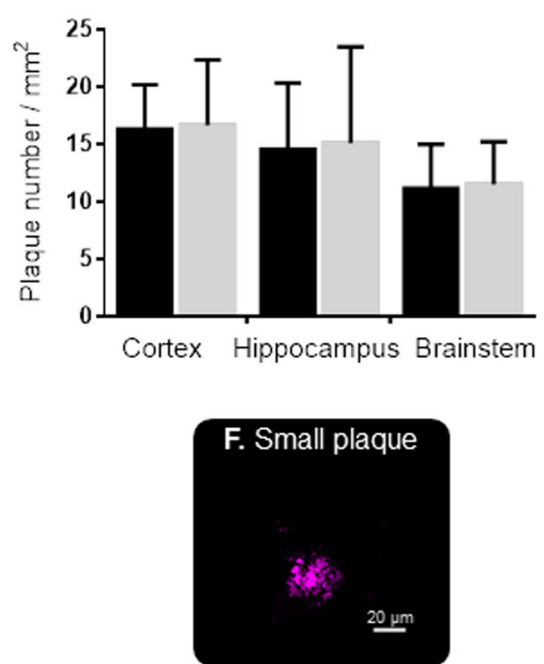

D. Medium $A \beta_{[37-42]}$ plaques

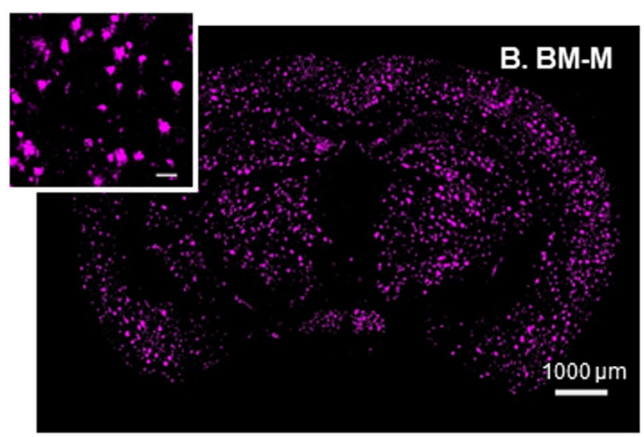

E. Large $A \beta_{[37-42]}$ plaques
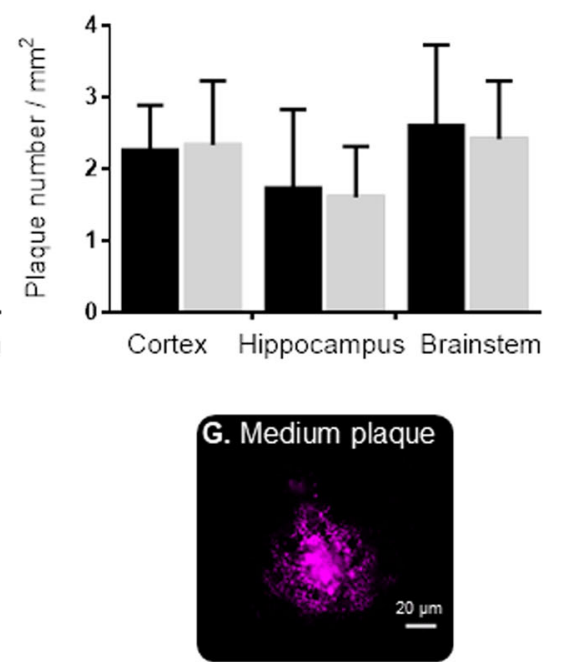
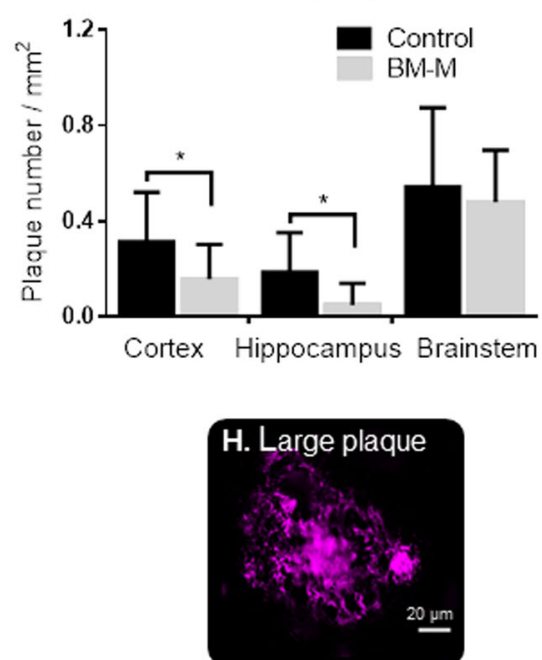

Fig. $3 A \beta_{[37-42]}$ plaques number decrease in cortex and hippocampus of APP/PS1 mice treated with BM-M. a, b Representative $A \beta_{[37-42]}$ plaques immunostaining comparison between PBS injected mice (control) and BM-M treated mice, showing less large plaques in transplanted animals. c-e Small, medium and large plaque number per $\mathrm{mm}^{2}$ in cortex, hippocampus and brainstem comparison between control and BM-M treated mice showing a reduction of larger plaque in cortex and hippocampus. $\mathbf{f}-\mathbf{h}$ Representative images of different plaque sizes stained by immunohistochemistry are shown. Bar graphs display the mean \pm SEM (error bars) of plaque $\left({ }^{*} p<0.05\right)$ 
$A \beta_{[37-42]}$ numbers and size

Abeta $_{[37-42]}$ covers the bulk of amyloid in AD brains in this mouse model [16] and was used to quantify the changes after BM-M transplantations. Twenty-eight days after administration of BM-M or PBS, mice brains were evaluated for changes in $A \beta$ deposition. The number and size of plaques were quantified in cortex, hippocampus and brainstem individually as these regions are differently loaded with amyloid plaques in this mouse model [17]. We found that transplantation of BM-M resulted in $9 \%(p<0.05)$ reduction of plaque size in the hippocampus only (Fig. 2). Although we could not detect a change in total $\mathrm{A} \beta_{[37-42]}$ plaque numbers, our data shows that transplantation resulted in a reduction of the number of larger plaques $\left(>1500 \mu \mathrm{m}^{2}\right)$ particularly in the cortex $(50 \%, p<0.03)$ and hippocampus $(70 \%, p<$ 0.02) (Fig. 3). These results suggest that there is an effect mediated by the transplanted $B M-M$ on the $A \beta_{[37-42]}$ plaques and that this is more pronounced in the hippocampus and for larger plaques.

\section{$A \beta-p E 3$ numbers and size}

To evaluate the ability of the transplanted BM-M to invade the core of amyloid plaques we also quantified one of the modified amyloid forms known to be resistant to proteolysis and often found in the center of plaques - the pyroglutamate-modified $A \beta$ peptide $(A \beta$ pE3) [18]. Double staining of $A \beta_{[37-42]}$ and $A \beta-p E 3$ clearly confirms this composition of amyloid plaque types in our mouse model (Fig. 2f). No differences were found regarding the number or size of $A \beta-p E 3$ plaques, neither in total brain area nor in the different brain regions analyzed (Fig. 4), which indicates that under the current transplantation conditions, $B M-M$ cells do not have an impact on this subgroup of $A \beta$ plaques (Fig. $4 f-h$ ).

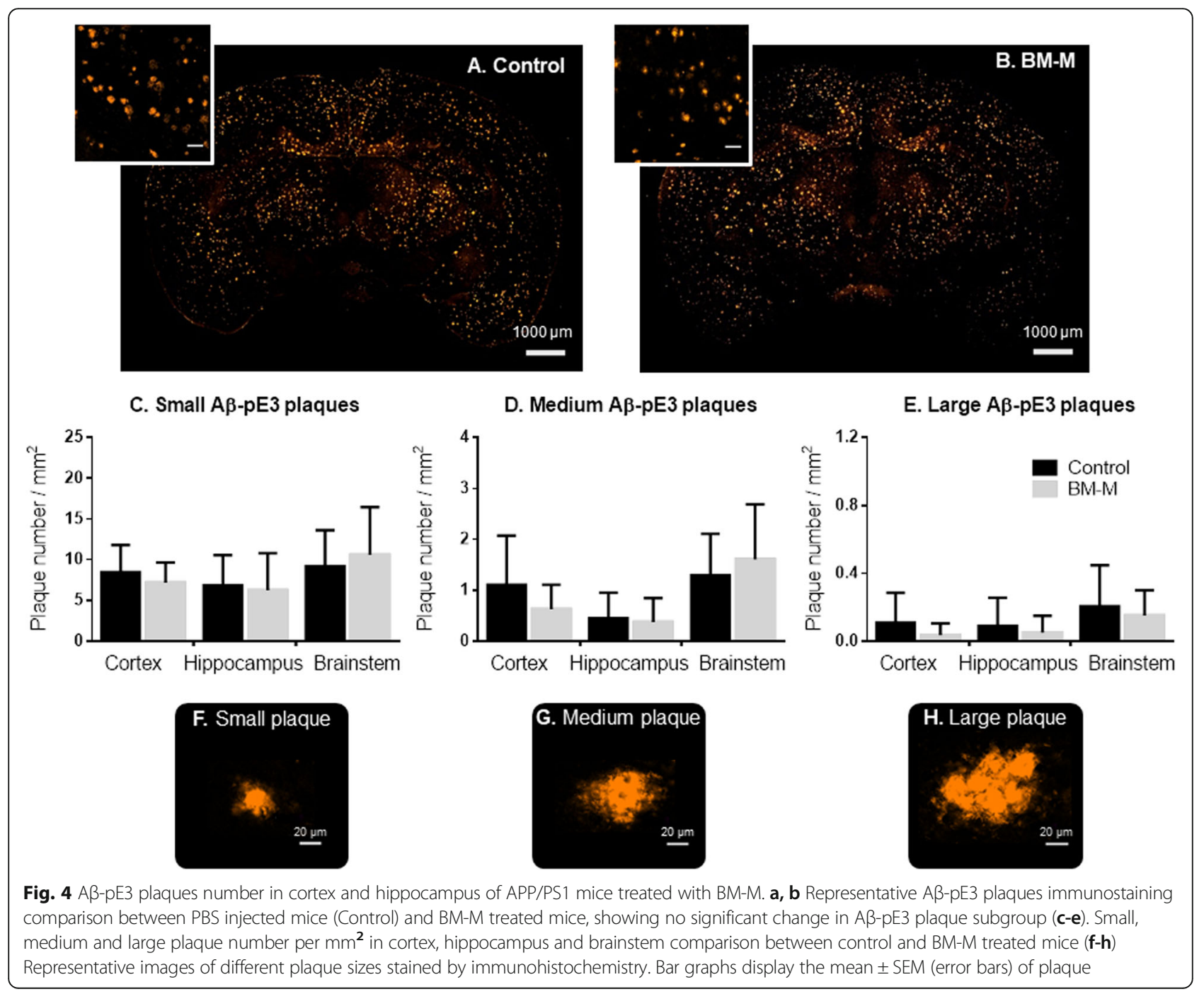


Microglia (IBA- $1^{+}$) numbers

We evaluated different microglia cell sizes - small microglia cells $\left(<300 \mu \mathrm{m}^{2}\right)$, cluster of microglia I (300$\left.900 \mu \mathrm{m}^{2}\right)$ and cluster of microglia II $\left(>900 \mu \mathrm{m}^{2}\right)$.

BM-M transplantation was associated with an increased incidence of small microglia but had no effect on microglia clusters (associated with high microglia activation) (Fig. 5a-e). Our data shows an increase compared to controls in the number of small microglia in the hippocampus only (20\%, $p<0.03$ - Fig. 5c), which links to the results shown above for $A \beta$ plaque content. Observationally, when co-staining IBA-1 with $A \beta_{[37-42]}$, the association of large microglia clusters with large $A \beta$ plaques was evident, while small soma cells were generally not associated with plaque colocalization (Fig. $5 \mathrm{f}-\mathrm{h}$ ).

\section{Astrocytes}

Using immunohistochemistry, the total area covered by astrocytes showed a decrease in the treated animals compared to controls $(23 \%, p<0.02)$ particularly in the brainstem $(37 \% ; p<0.03)$ (Fig. 6). The decrease indicates a reduction of astrocyte activation which in turn is associated with reduced neuroinflammation [19] .

\section{BM-M effect on gene and protein expression}

Expression of the following genes was significantly reduced in the hippocampus of the transplanted group compared to controls: IL-6 $(44 \%, p<0.05)$, IFN- $\gamma(26 \%$, $p<0.05)$, PTGER-2 $(18 \%, p<0.012)$ (Fig. 7)

IL-10 expression was lowered in hippocampus $(56 \%, p<$ $0.02)$ but elevated in the cortex $(26 \%, p<0.04)$. These results suggest that there is a decrease in neuroinflammation -

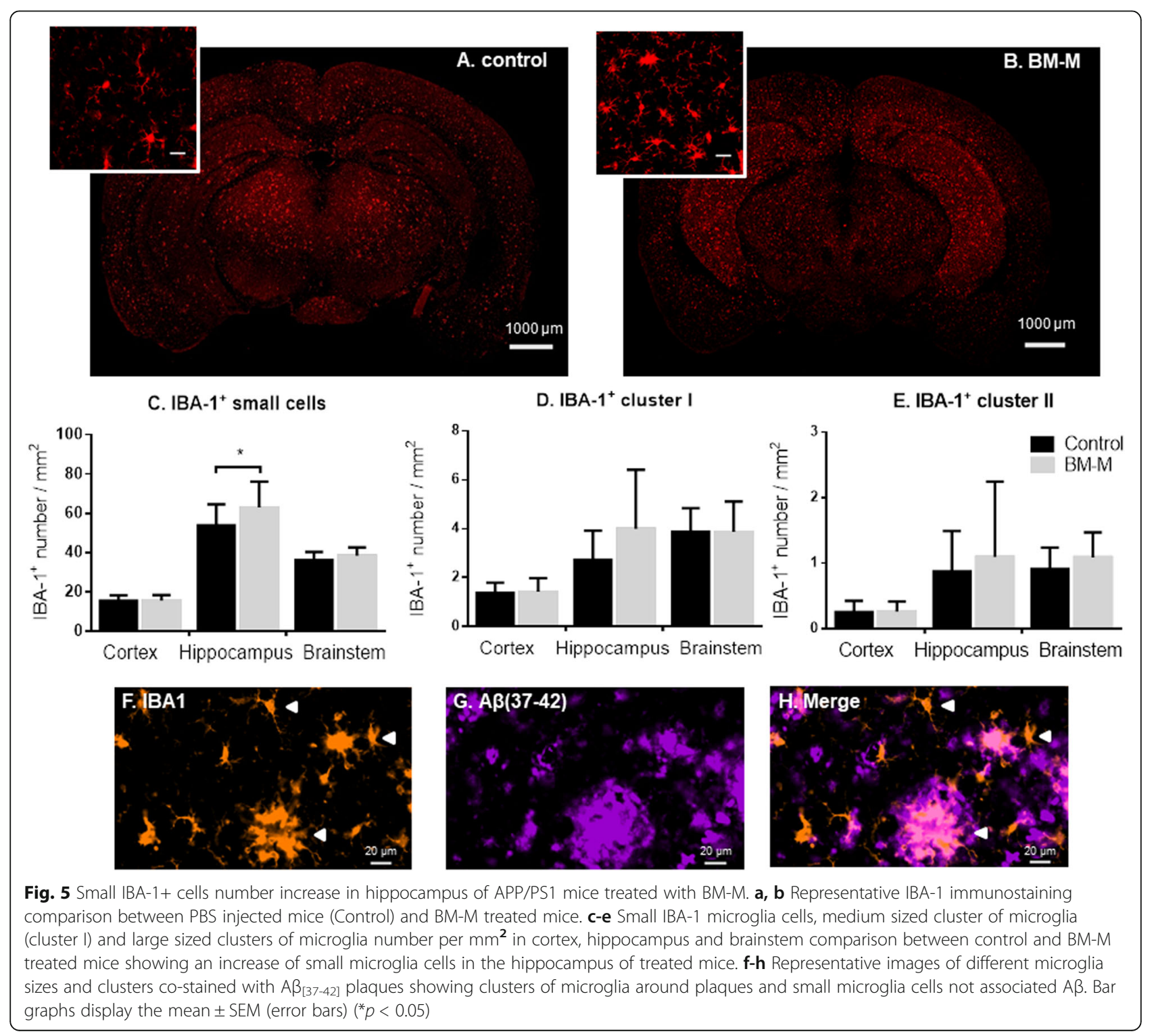




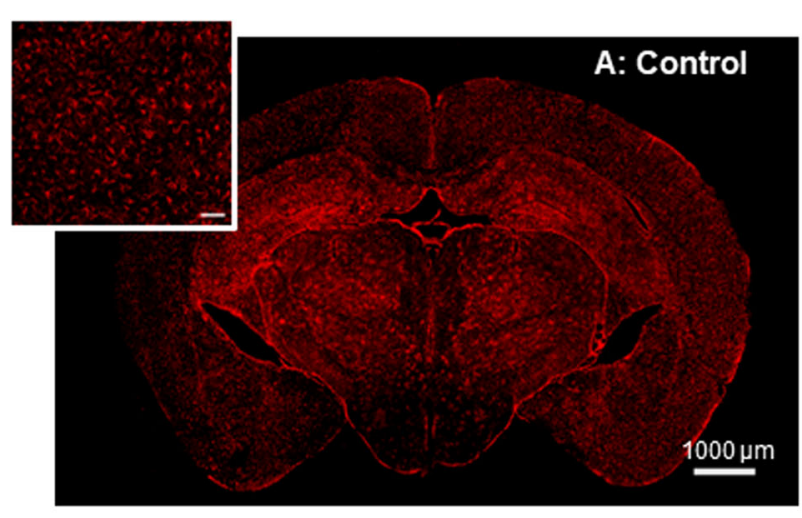

C. $\mathrm{GFAP}^{+}$area covered

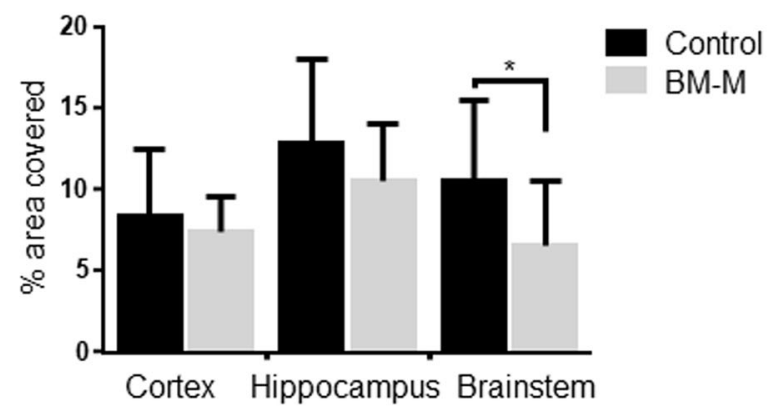

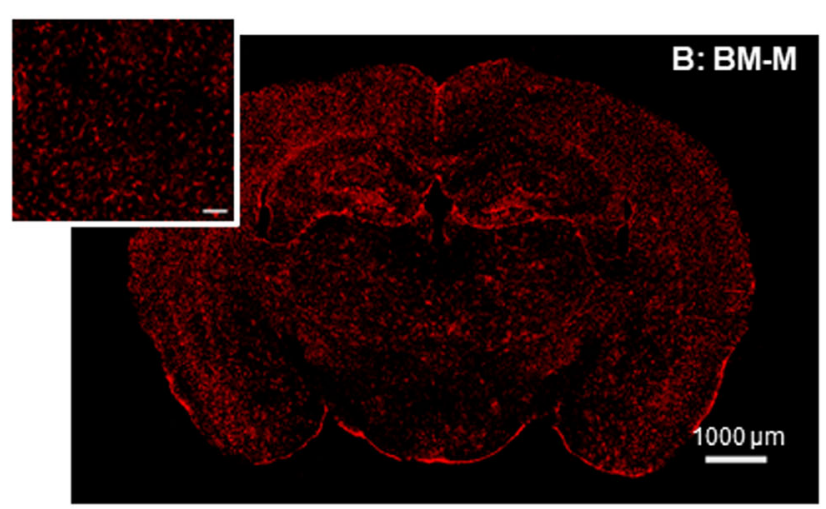

D. $\mathrm{GFAP}^{+}$area covered in total brain area



Fig. 6 GFAP (astrocytes) area covered decreases on APP/PS1 mice treated with BM-M. a, b Representative GFAP immunostaining comparison between PBS injected mice (control) and BM-M treated mice showing less area covered by GFAP in the brains of the transplanted mice group. c Percentage of GFAP+ area covered in cortex, hippocampus and brainstem individually, shows a significant decrease in the brain stem area of BM$M$ treated mice. Bar graphs display the mean \pm SEM (error bars) $\left({ }^{*} p<0.05\right)$. d Percentage of GFAP+ area covered in total brain area shows a significant reduction upon BM-M transplantation

particularly in the hippocampus- of the mice that received BM-M.

No changes were observed for: Neuronal Growth Factor (NGF) gene expression or protein levels of acetylcholine (Neurotrophic support); monocyte chemoattractant protein 1 (MCP-1) gene expression (chemotaxis); TREM-2 (phagocytotic activity) and GFAP protein levels (Fig. 8).

\section{Discussion}

In previous studies, we demonstrated that microglia cells can be reliably generated in vitro [20]. It should be noted that while in this study, the level of CD206+ in BM-M was comparatively low compared to other 'classic' M2 markers, Microglia are generally found to be lower expressing for CD206 compared to blood macrophages [21]. There are three studies that have some similarity [10-13]. However, these either use an exogenous injection of $A \beta$ as an $\mathrm{AD}$ animal model (which is associated with brain regional limitations) or use a different cell type (monocytes) or different age ranges. In the current study setting, we used a transgenic mouse model that shows accumulation of $A \beta$ throughout time in several regions of the brain, moreover we have used BM-M cells and not monocytes, which have a higher resemblance with the microglia cells that are present in the brain as they are more differentiated and primed.

In a previous study, we tracked enhanced green fluorescent protein (eGFP) marked microglia intravenously transplanted to the brains of aged mice 28 days after transplantation [13]. We are therefore confident that the transplanted $\mathrm{BM}-\mathrm{M}$ reach the site of investigation. In the present study, we have the advantage of obtaining results with cells that are more representative of a future clinical study, i.e., non-eGFP labelled. On the other hand this brings a limitation, since it is not possible to obtain a quantification relationship between the number of cells that reached the brain and the observed effects. What cannot be determined however, is to what extent the observed effects are directly attributable to 'standard' activity by the BM-M themselves or alternatively to secondary immunological reactions associated with the (potentially transient) presence of BM-M. 

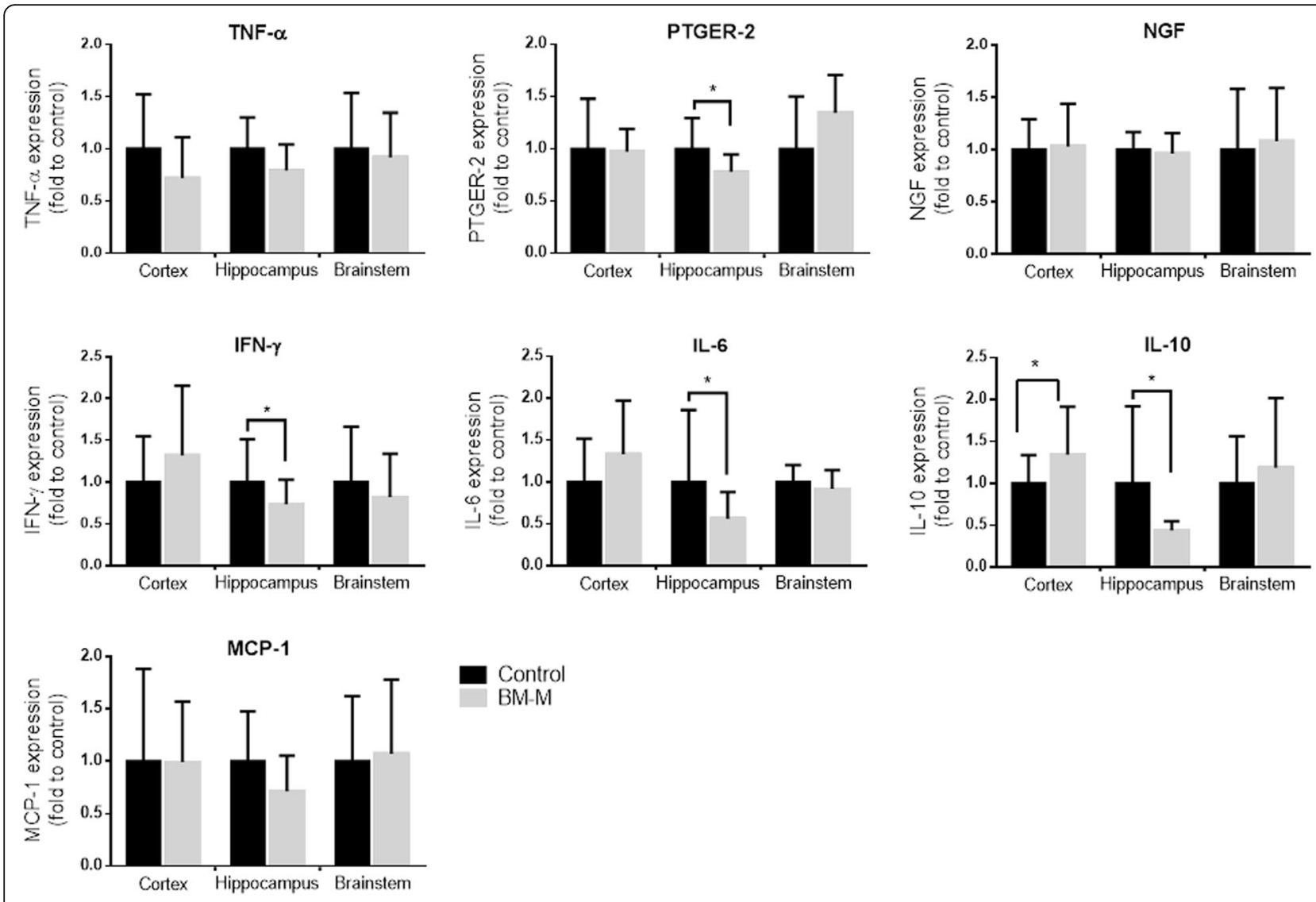

Fig. 7 Treatment with BM-M resulted in reduced levels in inflammation markers in the hippocampus of APP/PS1 treated mice. mRNA expression of inflammation markers PTGER2, IFN-Y, IL-6 and IL-10 was reduced in the hippocampus of APP/PS1 which received BM-M $(n=6)$ compared to PBS injected control group $(n=6)$. Values were normalized to $36 B 4$ level. Bar graphs display the mean \pm SEM (error bars). Statistical significances are represented as $* P<0.05$

\section{Amyloid clearance}

Our data shows that systemically transplanted BM-M are associated with a decrease in $\mathrm{A} \beta$ plaque size, especially in the hippocampus. We assume that BM-M transplantation improved the clearance of the diffuse halo of larger plaques: $\mathrm{A} \beta$ dense-core plaques are usually surrounded by more soluble diffuse $A \beta$ material $[22,23]$ a neuropathological feature of AD consistently observable in transgenic mouse models such as APP/PS1 [17]. In contrast, A $\beta$ pE3 is more hydrophobic, with higher aggregation propensity and stability [24] and more resistant to degradation [25-27] - all factors that may explain the




lack of changes observed in the content of the $A \beta$ pE3 peptide following a single dose BM-M transplant.

\section{Neuroinflammation}

Neuroinflammation is one of the main hallmarks of $\mathrm{AD}$ [28]. Factors IL-6, IL-10, IFN- $\gamma$ and PTGER-2 that are generally observed to be elevated in AD patients [29-31] were found to be reduced in the hippocampus of BM-M transplanted mice.

While expression of IL-10 was reduced in the hippocampus, it was elevated in cortex of the treated mice. While we cannot currently account for the observation, it is line with a general finding:

\section{Hippocampus}

Many observed effects (reduction in average $A \beta_{[37-42]}$ plaque size; increase in small IBA- $1^{+}$cells numbers; reduction of neuroinflammation-associated gene expression) were statistically proven only the hippocampus region.

Microglia are particularly prevalent in the hippocampus [32], and regulated by their microenvironment [33]. Thus, the consistently stronger effect we tend to observe may be due to a quicker propagation of anti-inflammatory cytokines produced by the transplanted M2 BM-M.

The one departure from this trend was the reduction of reactive astrocytes following BM-M-transplants, which was significantly more pronounced in the brainstem, not in the hippocampus.

\section{Conclusion}

Our results provide further evidence how BM-M transplantation may be impacting hallmarks of $\mathrm{AD}$ pathology: the observed reduction in average $A \beta_{[37-42]}$ plaque size; and in some neuroinflammation-associated gene expression while coupled with an increase in small IBA- $1^{+}$cells numbers may point to a potential therapeutic utility in microglia-focussed regenerative medicine.

While we could mainly demonstrate the observed effects for the hippocampus, larger trials are needed to verify whether these effects are lasting and ubiquitous with respect to $\mathrm{AD}$ pathology.

\section{Abbreviations \\ AChE: Acetylcholinesterase; AD: Alzheimer's disease; $A B$ : Amyloid beta; $A B-$ pE3: Pyroglutamate-modified A $\beta$ peptide; BM-M: Bone marrow derived macrophages; CNS: Central nervous system; eGFP: Green fluorescent protein (eGFP); GFAP: Glial fibrillary acidic protein; MCP-1: Monocyte chemoattractant protein 1; NGF: Neuronal Growth Factor; PBS: Phosphate buffered saline; TREM-2: Triggering receptor expressed on myeloid cells 2}

\section{Acknowledgements}

Guillaume Provost helped with the IBA histology and Piotr Pawlick helped with the GFAP histology evaluation. We thank Sebastian Sethe for his help in drafting, writing and editing the manuscript.

\section{Authors' contributions}

AS designed the experiment, conducted the cell transplantations, organ isolations and wrote the draft of the manuscript. LMCM conducted the histology, ELISA, PCR experiments. CL generated the BM-M, SS conducted the brain isolation and performed animal blinding procedures, CF established and optimized PCRs, KA performed the FACS analysis of the microglia. All authors read and approved the final manuscript.

\section{Funding}

The study was funded by the Fraunhofer Gesellschaft, Longecity and the EPSRC.

\section{Availability of data and materials}

The datasets used and/or analysed during the current study are available from the corresponding author on reasonable request.

\section{Ethics approval and consent to participate}

Animal transplantations were performed according to the UK Animals (Scientific Procedures) Act 1986, under Home Office project license 40/3601.

\section{Consent for publication}

All authors critically revised the manuscript and approved the final version before submission.

\section{Competing interests}

The authors declare that they have no competing interests.

\section{Author details}

${ }^{1}$ Centre for Biological Engineering, School of Mechanical, Electrical and Manufacturing Engineering, Loughborough University, Epinal Way, Loughborough, UK. ${ }^{2}$ Fraunhofer Institute for Cell Therapy and Immunology, Leipzig, Germany. ${ }^{3}$ School of Life Sciences, Queens Medical Centre, University of Nottingham, Nottingham, UK. ${ }^{4}$ Leipzig University, Leipzig, Germany.

Received: 2 August 2018 Accepted: 10 September 2019

Published online: 14 October 2019

\section{References}

1. Zhao R, Hu W, Tsai J, Li W, Gan W-B. Microglia limit the expansion of $\beta$ amyloid plaques in a mouse model of Alzheimer's disease. Mol Neurodegener. 2017;12:47.

2. Lai AY, McLaurin J. Clearance of amyloid- $\beta$ peptides by microglia and macrophages: the issue of what, when and where. Future Neurol. 2012; 7(2):165-76.

3. Serrano-Pozo A, Gómez-Isla T, Growdon JH, Frosch MP, Hyman BT. A phenotypic change but not proliferation underlies glial responses in Alzheimer disease. Am J Pathol. 2013;182(6):2332-44.

4. Mills CD. M1 and M2 macrophages: oracles of health and disease. Crit Rev Immunol. 2012;32(6):463-88.

5. Swirski FK, Hilgendorf I, Robbins CS. From proliferation to proliferation: monocyte lineage comes full circle. Semin Immunopathol. 2014;36(2):137-48.

6. Hamelin L, Lagarde J, Dorothee G, Leroy C, Labit M, Comley RA, de Souza LC, Corne H, Dauphinot L, Bertoux M, et al. Early and protective microglial activation in Alzheimer's disease: a prospective study using 18F-DPA-714 PET imaging. Brain. 2016;139(Pt 4):1252-64.

7. Stolzing A, Sethe S, Grune T. Chronically active: activation of microglial proteolysis in ageing and neurodegeneration. Redox Rep. 2005;10(4):207-13.

8. Krabbe G, Halle A, Matyash V, Rinnenthal JL, Eom GD, Bernhardt U, Miller KR, Prokop S, Kettenmann H, Heppner FL. Functional impairment of microglia coincides with Beta-amyloid deposition in mice with Alzheimer-like pathology. PLOS One. 2013:8(4):e60921.

9. Mosher Kl, Wyss-Coray T. Microglial dysfunction in brain aging and Alzheimer's disease. Biochem Pharmacol. 2014:88(4):594-604.

10. Takata K, Kitamura Y, Yanagisawa D, Morikawa S, Morita M, Inubushi T, Tsuchiya D, Chishiro S, Saeki M, Taniguchi T, et al. Microglial transplantation increases amyloid-beta clearance in Alzheimer model rats. FEBS Lett. 2007; 581(3):475-8.

11. Hohsfield LA, Humpel C. Intravenous infusion of monocytes isolated from 2week-old mice enhances clearance of Beta-amyloid plaques in an Alzheimer mouse model. PLoS One. 2015;10(4):e0121930.

12. Zhu D, Yang N, Liu YY, Zheng J, Ji C, Zuo PP. M2 macrophage transplantation ameliorates cognitive dysfunction in amyloid-beta-treated rats through regulation of microglial polarization. J Alzheimers Dis. 2016;52(2):483-95. 
13. Leovsky C, Fabian C, Naaldijk Y, Jager C, Jang HJ, Bohme J, Rudolph L, Stolzing A. Biodistribution of in vitro-derived microglia applied intranasally and intravenously to mice: effects of aging. Cytotherapy. 2015;17(11):1617-26.

14. Moreno-Gonzalez I, Edwards lii G, Salvadores N, Shahnawaz M, DiazEspinoza R, Soto C. Molecular interaction between type 2 diabetes and Alzheimer's disease through cross-seeding of protein misfolding. Mol Psychiatry. 2017;22(9):1327-34.

15. Chey S, Claus C, Liebert UG. Improved method for simultaneous isolation of proteins and nucleic acids. Anal Biochem. 2011;411(1):164-6.

16. Wirths $\mathrm{O}$, Breyhan $\mathrm{H}$, Cynis $\mathrm{H}$, Schilling $\mathrm{S}$, Demuth $\mathrm{H}-\mathrm{U}$, Bayer TA Intraneuronal pyroglutamate-Abeta 3-42 triggers neurodegeneration and lethal neurological deficits in a transgenic mouse model. Acta Neuropathol. 2009;118(4):487-96.

17. Radde R, Bolmont T, Kaeser SA, Coomaraswamy J, Lindau D, Stoltze L, Calhoun ME, Jaggi F, Wolburg H, Gengler S, et al. Abeta42-driven cerebral amyloidosis in transgenic mice reveals early and robust pathology. EMBO Rep. 2006;7(9):940-6.

18. Sullivan CP, Berg EA, Elliott-Bryant R, Fishman JB, McKee AC, Morin PJ, Shia $M A$, Fine RE. Pyroglutamate-A 3 and 11 colocalize in amyloid plaques in Alzheimer's disease cerebral cortex with pyroglutamate-A $\beta 11$ forming the central core. Neurosci Lett. 2011;505(2):109-12.

19. Osborn LM, Kamphuis W, Wadman WJ, Hol EM. Astrogliosis: an integral player in the pathogenesis of Alzheimer's disease. Prog Neurobiol. 2016; 144(Supplement C):121-41.

20. Hinze A, Stolzing A. Differentiation of mouse bone marrow derived stem cells toward microglia-like cells. BMC Cell Biol. 2011;12:35.

21. Melief J, Koning N, Schuurman KG, Van De Garde MD, Smolders J, Hoek RM, Van Eijk M, Hamann J, Huitinga I. Phenotyping primary human microglia: tight regulation of LPS responsiveness. Glia. 2012;60(10):1506-17.

22. Condello C, Schain A, Grutzendler J. Multicolor time-stamp reveals the dynamics and toxicity of amyloid deposition. Sci Rep. 2011;1:19.

23. Wang A, Das P, Switzer RC 3rd, Golde TE, Jankowsky JL. Robust amyloid clearance in a mouse model of Alzheimer's disease provides novel insights into the mechanism of amyloid-beta immunotherapy. J Neurosci. 2011; 31(11):4124-36.

24. D'Arrigo C, Tabaton M, Perico A. N-terminal truncated pyroglutamyl beta amyloid peptide Abetapy3-42 shows a faster aggregation kinetics than the full-length Abeta1-42. Biopolymers. 2009;91(10):861-73.

25. De Kimpe L, van Haastert ES, Kaminari A, Zwart R, Rutjes H, Hoozemans JJM, Scheper W. Intracellular accumulation of aggregated pyroglutamate amyloid beta: convergence of aging and $A \beta$ pathology at the lysosome. Age. 2013;35(3):673-87.

26. Russo C, Violani E, Salis S, Venezia V, Dolcini V, Damonte G, Benatti U, D'Arrigo C, Patrone E, Carlo P, et al. Pyroglutamate-modified amyloid $\beta$ peptides - $\mathrm{A} \beta \mathrm{N} 3(\mathrm{pE})$ - strongly affect cultured neuron and astrocyte survival. J Neurochem. 2002;82(6):1480-9.

27. Jawhar S, Wirths O, Bayer TA. Pyroglutamate amyloid-beta (Abeta): a hatchet man in Alzheimer disease. J Biol Chem. 2011;286(45):38825-32.

28. Rubio-Perez JM, Morillas-Ruiz JM. A review: inflammatory process in Alzheimer's disease, role of cytokines. Scientific World J. 2012;2012:756357.

29. Montine TJ, Milatovic D, Gupta RC, Valyi-Nagy T, Morrow JD, Breyer RM. Neuronal oxidative damage from activated innate immunity is EP2 receptordependent. J Neurochem. 2002;83(2):463-70.

30. Gadient RA, Otten UH. Interleukin-6 (IL-6)-a molecule with both beneficial and destructive potentials. Prog Neurobiol. 1997;52(5):379-90.

31. Zheng C, Zhou X-W, Wang J-Z. The dual roles of cytokines in Alzheimer's disease: update on interleukins, TNF-a, TGF- $\beta$ and IFN- - . Transl Neurodegener. 2016;5:7.

32. Lawson LJ, Perry VH, Dri P, Gordon S. Heterogeneity in the distribution and morphology of microglia in the normal adult mouse brain. Neuroscience. 1990;39(1):151-70

33. Perry VH, Teeling J. Microglia and macrophages of the central nervous system: the contribution of microglia priming and systemic inflammation to chronic neurodegeneration. Semin Immunopathol. 2013;35(5):601-12.

Ready to submit your research? Choose BMC and benefit from:

- fast, convenient online submission

- thorough peer review by experienced researchers in your field

- rapid publication on acceptance

- support for research data, including large and complex data types

- gold Open Access which fosters wider collaboration and increased citations

- maximum visibility for your research: over $100 \mathrm{M}$ website views per year

At $\mathrm{BMC}$, research is always in progress.

Learn more biomedcentral.com/submissions 